\title{
Investigation and Research on Chinese Jianhe Tin Embroidery Technology*
}

\author{
Xiaochen Geng \\ Xiamen Academy of Arts and Design \\ Fuzhou University \\ Xiamen, China \\ Postdoctoral Programs of Design Science \\ Nanjing Normal University \\ Nanjing, China
}

\author{
Jinna Ren \\ Xiamen Academy of Arts and Design \\ Fuzhou University \\ Xiamen, China
}

\begin{abstract}
This paper briefly describes the area and distribution of tin embroidery, and interprets the weaving, dyeing, picking, embroidering and other processes of tin embroidery through field investigation and research. Based on the detailed discussion of the craft features of tin embroidery, the paper also analyzes the beauty of tin embroidery and the creation view of craftsmanship, which also has a positive significance for the protection of China's intangible cultural heritage and integration with modern design.
\end{abstract}

\section{Keywords-tin embroidery; craftwork; creation view}

\section{INTRODUCTION}

The ancient Chinese literature "Kaogong Ji" contains "The sky has times, the earth has air, the material has beauty, the craftwork has skills, the combination of these four factors can be called good", this is the ancient Chinese concept of creation, meaning everything must design from the whole system of nature and the era, and finally reflects a design concept of "Harmony". China's Jianhe tin embroidery is also followed the basic principles of creation, whether it is in the material selection or in the craftwork, it all reflects the creation concept of beautiful material and skillful craftsmanship in ancient Chinese design.

\section{THE GEOGRAPHICAL DISTRIBUTION OF TIN EMBROIDERY}

Tin embroidery is mainly distributed in the villages of Nanzhai Township, Mindong Township and Nanjia Town on the banks of the middle and lower reaches of Qingshui River in Jianhe County. Tin embroidery uses metal tin instead of a wire as the main material for embroidery, especially the Liu $\mathrm{Fu}$ tin embroidery in Nanzhai Township is the most famous. Due to the particularity and uniqueness of its metallic tin, tin embroidery was included in the first batch of national intangible cultural heritage protection list in 2005. The complexity of the tin embroidery process is closely related to

*2014, China National Social Science Fund, project number: 2014CG134, phased result

2015, China Postdoctoral Science Found, project number: 2015M570465, phased result

2015, High-level university construction project, Art theoretical discipline support project of Fuzhou University, finished project result. the farming culture of the Miao people's tin embroidery branch, reflecting the persistent pursuit of beauty and the longing of life in the self-sufficient culture of Miao people.

Miao people's tin embroidery process is the most complicated, and the pattern is the most beautiful. The whole tin embroidery is mainly distributed in four places of women's clothing, front skirt, rear skirt and the back part are all tin embroidery. The front and rear skirt are singularly embroidered piece and wrapped around the pleated skirt in the form of a tie. The back embroidered piece and the raindrop line wrapped in the tin at lower end, the raindrop line has three sections wrapped in tin and sewn on the back of the top clothes. A small portion on the left and right parts of the top in front of and is wrapped in a pattern of tin (see "Fig. 1" "Fig.2").

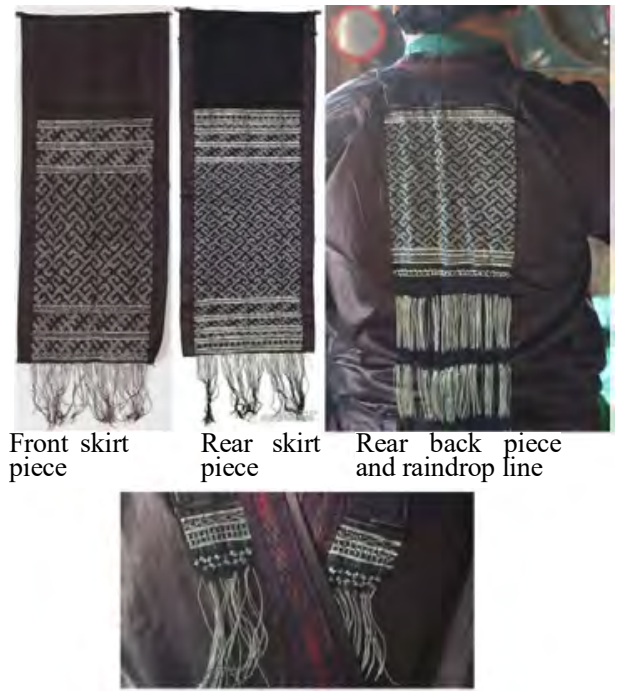

Fig. 1. Tin Embroidery pattern. 


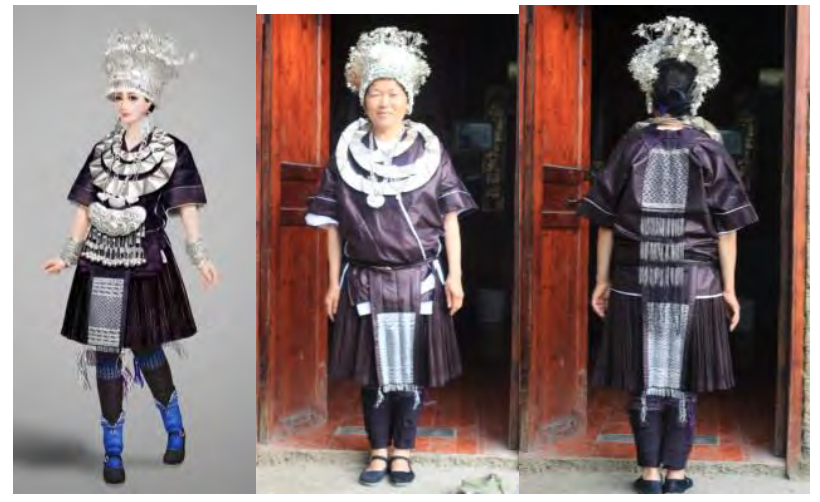

Fig. 2. Overall clothing features of tin embroidery.

\section{THE PROCESS OF TIN EMBROIDERY}

The process of tin embroidery can be regarded as a great miracle in human history. It is extremely complex and rare so it is especially precious. On both sides of the lush Qingshui River, the tin embroidery branch people using their own wires to write the story of their ancestors' lives, hide their wisdom in the needles and threads of tin embroidery. The whole process of tin embroidery is divided into four parts: weaving, dyeing, picking and embroidering. Weaving and dyeing the plain weave fabric with hardness is the first step of tin embroidery, the choice of tin embroidery for the base fabric has certain requests, the density and softness of the cloth affect the arrangement of the tin embroidery pattern. Picking and embroidering are the main techniques of tin embroidery, which is an important means to complete the tin embroidery pattern. The connection of these four parts makes the tin embroidery finally show the rigorous, exquisite and vivid artistic image. The whole process of tin embroidery is shown in the following four parts.

\section{A. Weaving Process}

The base fabric used in traditional tin embroidery all came from the self-made plain fabric, and the tools used are homemade spinning machines and weaving machines. The spinning woven fabric is still traditionally hand-spun, the cotton is twisted into strips and then drawn into yarn, and finally woven into a fabric using a conventional horizontal looms. The Liufu Miao people use a horizontal loom, one end of yarn is attached to the frame, and the other end is attached to the winding shaft, and fixed by the belt behind the waist of the weaving woman. When weaving, it relies on the weaver's body to tighten the yarn and them to make the operation [1] (see "Fig. 3"). ${ }^{1}$

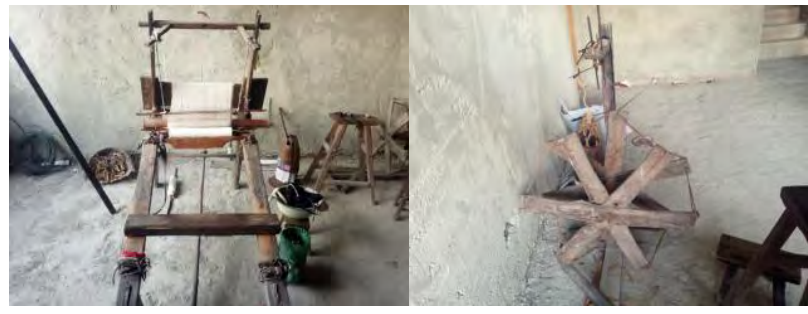

Fig. 3. Horizontal loom and spinning machine.

\section{B. Dyeing Process}

The dyeing cloth of the Miao people's tin embroidery branch is very particular: the season, the proportion of blue lake water, the dyeing time, the number of bleaching times, the amount of bovine gum, etc. These are all factors that affect the dyeing of cloth. If the weather is too cold, it is not easy to color, if it is too hot, the bovine gum is easy to melt, so too cold or too hot are all not suitable for dyeing cloth, the best time is from February to May of the lunar calendar, the whole process depends entirely on the Miao tin embroidery women to master the interaction relationship between the weather and vegetable dyes.

Tools and materials for dyeing cloth: dyeing barrel, wooden board, wooden stick, hollow sieve, wooden hammer, etc. (see "Fig. 4"). Materials: blue sedge, rice wine, red bean water, lonicera edulis (see "Fig. 5"), grass ash water (alkali) (see "Fig. 6").

Indigo production: first put the lonicera edulis in the water and soak for three days. When the lonicera edulis are rotted and then pick up the rotten roots and thrown away, the indigo is formed and then add the lime and wait for half an hour, then pour off the water and stirred. After stirring, wait for the fermentation of the lonicera edulis and lime until the dye turned into blue indigo. The ratio of lonicera edulis and lime water is $5: 1$.

Grass ash: Add the burnt grass ash to the water to make a funnel-like shape, drain the hot water from the ash, and drained the grass ash water (including alkali), which is the traditional practice of tin embroidery. Nowadays, in order to save time, people began to go to the town to buy dietary alkali to soak water instead of grass gray water.

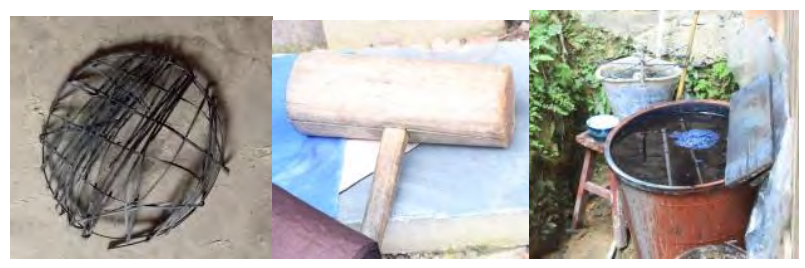

Fig. 4. Dyeing tools. 


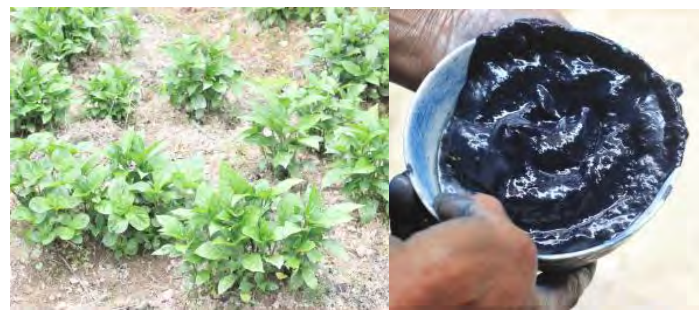

Fig. 5. Lonicera edulis and indigo.

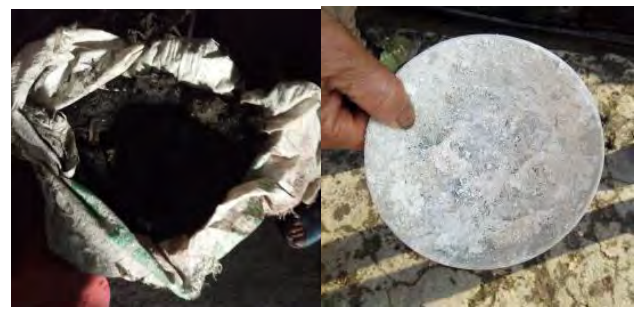

Fig. 6. Grass ash and dietary alkali.

Dyeing process: The whole process of dyeing cloth is extremely complicated and cumbersome. It takes about two months for a piece of dyed cloth to be completed. The overall process consists of dyeing cloth, washing cloth, tanning cloth, beetling cloth, steaming cloth. Every step of the process has to pay attention to it, according to certain steps. The completion of the dyed cloth is judged by the color and softness.

Dyeing water is a mix of indigo, grass ash water and shochu to make it ferment and wait for the water color to turn yellow, that is the traditional saying of "dead water" becomes "living water". A tank of dyed water requires more than three barrels of grass ash water, three bowls of indigo, adding half jin of rice wine. The proportion of dyed water is also crucial, and it takes about ten days to wait for them to ferment to yellow color then it is ready to dye the cloth. A sieve made of bamboo is placed in the dyeing tank in order to prevent the cloth from sinking and contact the powder in the bottom. After these are ready, the white cloth can be put into the tank for dye. The entire dyeing process is divided into three processes because it is too cumbersome.

The first procedure: 2 to 3 minutes after all the white cloth is soaked, both hands slide the cloth in the dyed water, take it out and put it on the board for 1 to 2 minutes and then soak it again. After repeating this action twice, and washed with clean water by three times, pat it with your hands unstopped and take it out to dry. (After each dyeing, add half bowl of indigo material, as a supplement of the dyed water, and stir with a wooden stick to make the indigo material fully melt into the water.) The color of the first dyeing cloth is blue, directly dyed again, wash, and then tan. The color changes from blue to dark blue.

The second procedure: After several times of dyeing, washing, tanning, etc., the color is suitable. Fold the tanned cloth and beat it for the first time, until the cloth is shiny and soft, then continue the process of dyeing, washing and tanning and start the second beating, after repeated dyeing, washing, tanning and beating, if the softness of the cloth is moderate then the bovine gum was started to apply. Bovine gum is also an important material for dyeing cloth. The traditional bovine gum is slowly boiled with cowhide (see "Fig. 8"). Due to various factors such as scientific advancement and time saving, it is now switched to artificially make granular yellow bovine gum (see "Fig. 7"). The amount of bovine gum is related to the amount of cloth A 3 foot cloth requires about 1 amount of glue.

Boiling process of bovine glue: Soak the bovine gum in water for about an hour until it became soft. Put a grass root (Miao language "Ge xiu"), smash it and put it into the water and boil it, Ge xiu (see "Fig. 9") (plant grass root, skin is gray and red and yellow inside). The purpose of Ge xiu is to enhance the color, probably stir for half an hour and then remove the root pieces. When the water boils, pour the bovine gum into the pot and boil for more than one hour when the water (see "Fig. 10") is yellow, it means the bovine gum is ready.

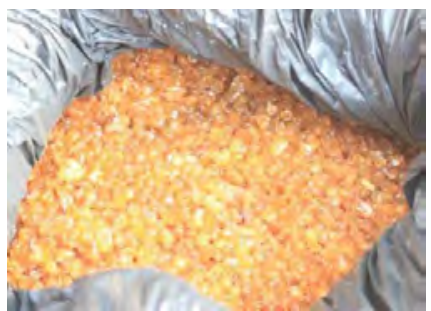

Fig. 7. Yellow grainy bovine gum.

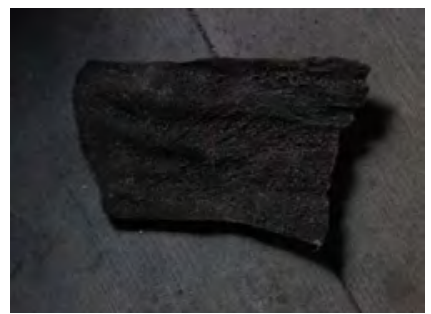

Fig. 8. Cowhide.

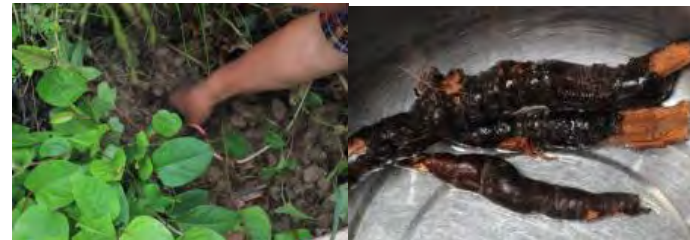

Fig. 9. "Ge xiu" in Miao.

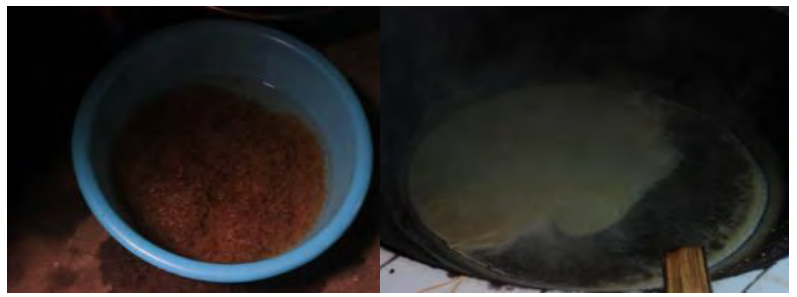

Fig. 10. Boiling bovine gum 
The third procedure: put a little red pepper in the beat cloth, pour the boiled bovine gum into the cloth, and take it to the shade to dry. After at least three times of dyeing, washing, drying, beating, and bovine gum applying process, the steaming stage can be carried out, put the beat cloth in a wooden bucket containing dry straw, the purpose of the straw is to keep warm. Then wrap the beat cloth with old cloth and covered with wooden cover. The whole boiling time is between 1 and 2 hours, and the fair should be moderate. After boiling, it shall go to dye, wash, dry, beat, and boil, repeat the previous process until the color is dark black. The whole process of cloth dyeing is complicated and cumbersome, the process of a piece of cloth: the number of dyeing, washing, beating and boiling should be no less than 6 times (see "Fig. 11").

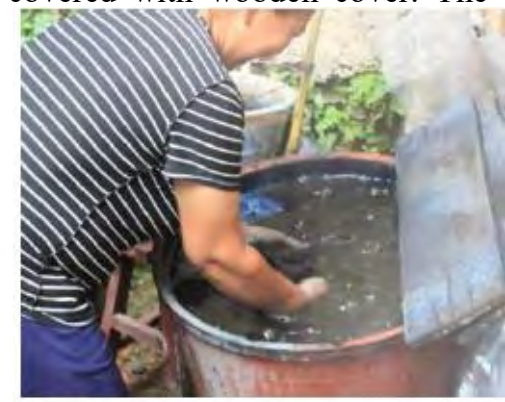

Dyeing cloth

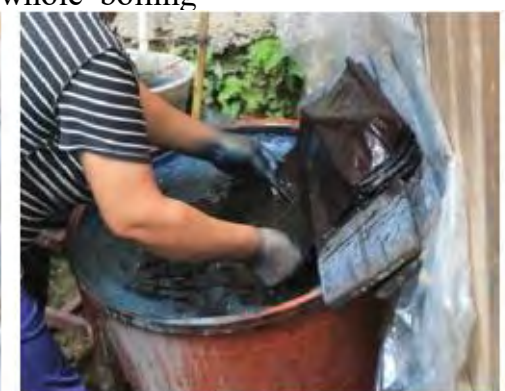

Placing wooden plate

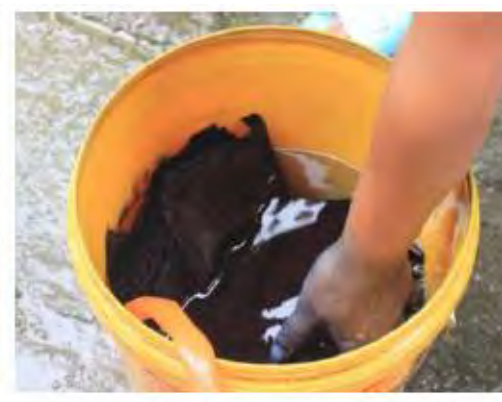

Washing cloth

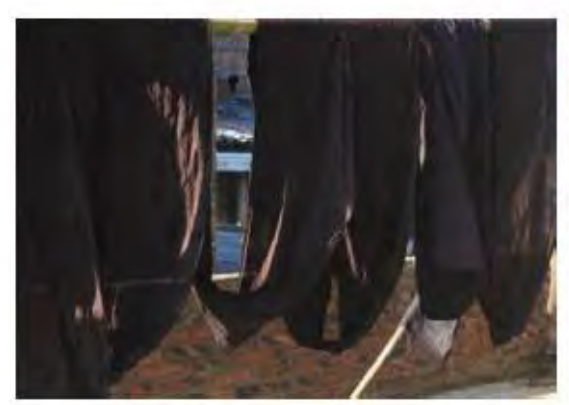

Tanning Cloth

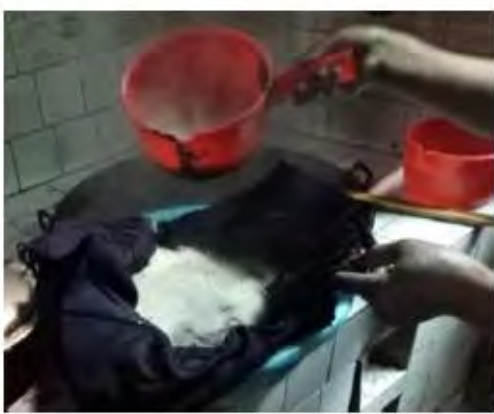

Applying bovine gum

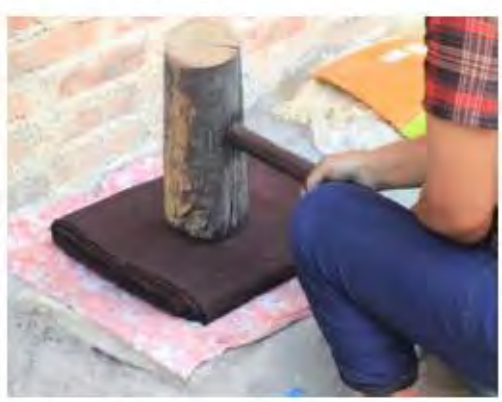

Beating cloth

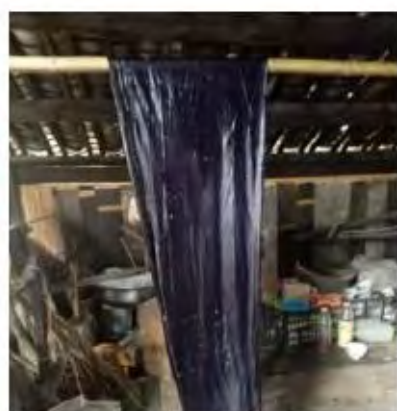

Drying cloth

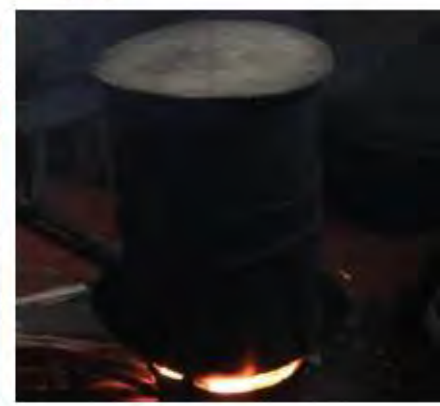

Boiling cloth

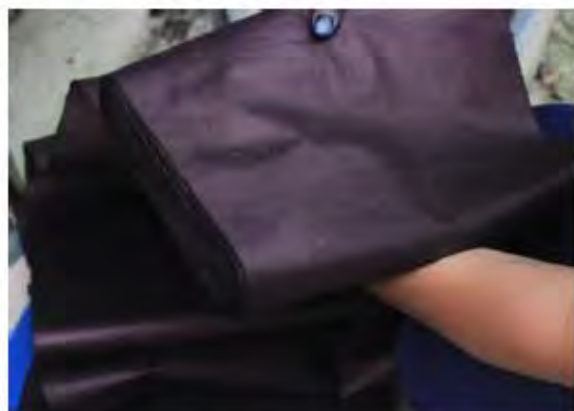

Dyed cloth

Fig. 11. Dyeing process.

From the whole dyeing process, we can see that the women of the Miao people's tin embroidery branch have mastered the relationship between vegetable dyes and climate, reflecting their creation concept of adapting to local conditions. It also reflects the industrious, simple and intelligent quality of Miao women.

It is precisely because the plain cloth used by the Miao people's tin embroidery is self-dyed, so it can't be stained with water, and the part that is stained with water will fade. At the same time, it will deform or fall off due to the tin property. These problems are the constraints and limitations of the process of tin embroidery itself. How to promote the tin embroidery market is very difficult, and it still needs constant exploration and practice.

\section{Picking Process}

Picking materials: main black cotton spinning thread, red, green, blue, black silk thread. The whole thread picking process is divided into two parts. The first part is to pick out the tin embroidery pattern with cotton spinning thread, and the second part embroiders the dark grid with purple, green, blue and red silk thread between the selected cotton spinning pattern gaps (see "Fig.12"). 


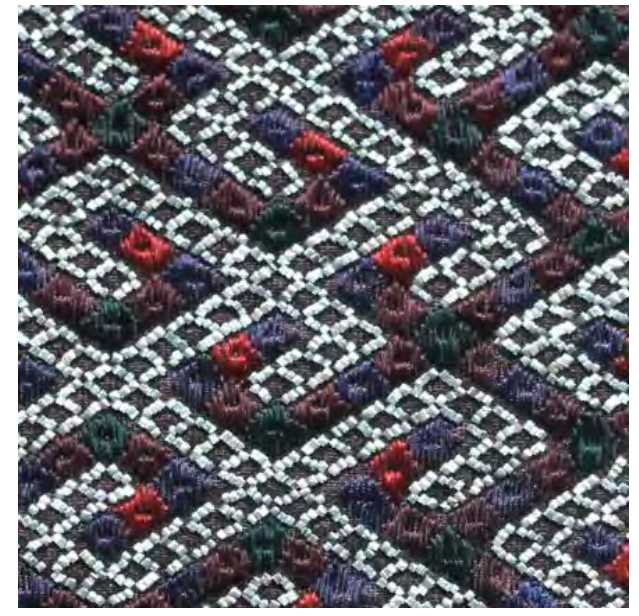

Fig. 12. Four-colored silk thread pattern.

Yarn embroidery: It is a traditional Chinese embroidery method, which is commonly used in the Miao nationality. The composition of the yarn embroidery is symmetrical and uniform, and the pattern is plain and simple. The characteristic of the yarn embroidery is the embroidery pattern is according to the geometric symmetry, the latitude and longitude of the yarn should be counted every time the thread is threaded, so as to ensure the accurate shape and regularity of the embroidered pattern. The base fabric is a cross-stitched line of latitude and longitude lines, so the base fabric becomes the best gauge for the pins. The technique of yarn embroidery is to count each latitude and longitude thread and then start the needle. The tin embroidery adopts the flat needle picking method of the yarn embroidery, such as the traditional square silk thread pattern of the Miao tin embroidery branch, and count three yarns from up and down, left and right, count three yearns from left and on the right also count three yearns to thread, so that could ensures the symmetry of the pattern. Especially the law of the threeneedle interval, this technique not only tests the human eyesight but also test the endurance. The technique of yarn embroidering mostly uses the opposite picking front display, and the tin embroidery thread uses this same technology. The four-color silk thread is also applied for the yarn embroidery technology, just the latitude and longitude lines are different. The tin embroidery branch is the first step of the tin embroidery technique. The tin embroidery patterns are mainly based on geometric abstract patterns, arranged regularly, simple and plain.

It should be indicated here that the three places where the tin embroidery mainly distributed are not all have the green, blue, and red dark patterns. The front skirt has no pattern composed of silk thread, only a silver-white tin embroidery pattern. Dark patterns are hidden in the back and rear skirt.

\section{Embroidered Tin and Tin Coating Process}

Embroidered tin materials and tools: tin sheet, scissors, fine needle

After completing the first process of tin embroidery, the pattern was picked and then the tin embroidery should be started. Tin sheet is the main material of tin embroidery. The old man of Liu Fu said that the early tin tablets were heated and melted into thin paper sheets. Later, people thought it too troublesome so they buy them from the vendors. Some of the modern tin pieces are brought back from Jianhe or Kaili. The use of tin for tin embroidery is mostly embroidered tin, and a small part is tin-coated. Embroidered tin is a tin wrapped in a pattern line, tin-coated is the same like that, but the two techniques are different. The traditional pattern is a square pattern, each square has three cotton threads on the top, bottom, left and right sides, that is, one square has three tins on the top, bottom, left and right. This is the traditional pattern tin embroidery, the old man from Zhanliu said that in order to make the pattern more beautiful, there appeared a more complicated tin embroidery pattern. Each tine wrapped with one line is the same. The specific embroidering process is to cut a tin bar into tin pieces $1 \mathrm{~mm}$ wide with scissors. The cut tin piece is too soft to rotate into a loop, press it with needle and straightened it. Before the tin embroidery, pick the embroidered pattern line with the needle to facilitate the penetration of the tin sheet, so that to avoid the embroidered pattern is too tight and the tin strip is too soft to pass through the thread. One end of the tin piece is cut into a triangle as the starting point of the insertion, and the other end is folded into a rectangle of $1-2 \mathrm{~mm}$ to hook the wire. After the triangle end of the tin piece insert into the pattern line, and pull it into the rectangle $1-2 \mathrm{~mm}$ that has just been folded at the other end. Hang the folded part of this end on the embroidered cotton thread and fold the rectangle of 1-2 mm with a fine needle. Press firmly to wrap the yarn, leave a tin bar of about $1-2 \mathrm{~mm}$, use the scissors to reduce the excess tin bar, and put the $1-2 \mathrm{~mm}$ tin bar left plain and flat, then complete the process of wrapping a line with rectangular tin pieces. All the lines of the tin embroidery pattern are use this technique (see "Fig. 13").

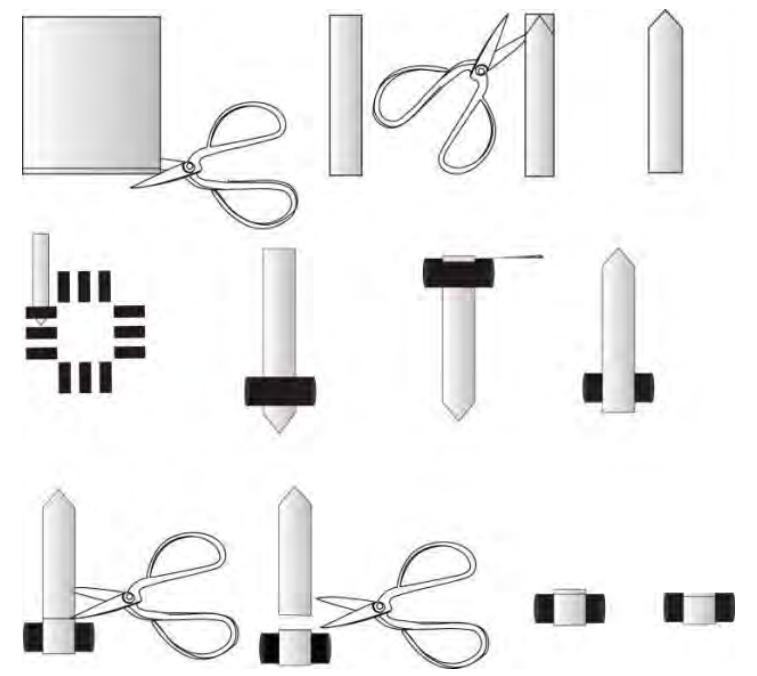

Fig. 13. The embroidered tin process.

The tin-coated part is mainly distributed on the left and right ends of the top of the coat collar, and the short stripes on the left and right ends are wrapped with tin, the long strips on the back are wrapped with tin, short strips part at the front and rear plate. There are two types of tin-coated. 
One is to directly wrap tin, cut tin bar about $6 \mathrm{~mm}$ wide and $15 \mathrm{~mm}$ long, and use a scissors to fold the $2 \mathrm{~mm}$ hook to directly cover the thread in the ditch. Wrap one end of the wire and fold the other end to directly wrap the line into a rectangular tin strip with a width of $2 \mathrm{~mm}$ and a length of 15 $\mathrm{mm}$. The other is a twist-like tin-coated, a tin bar with a width of $1 \mathrm{~mm}$, and a wire-wrapped spike in the form of a twist. This tin-coated requires skill, mainly wrapped in tin in the form of a rotating wire, and use the rotation force of the wire to make the tin strip wrapped on the wire spike. During the tin-coated process, rotated once and stop a while in order to make the wire loose up, if keep rotate the wire then the wire will be hard and the tin strip will be broken or fall off, or the wrapped pattern will become ugly. Therefore, the strength of the tin (see "Fig. 14") needs to be mastered. The tin that is wrapped is the finest and tightest, and the raindrops wrapped are the most beautiful. Every craft is so complicated, it tests the patience and perseverance of every embroidered woman.

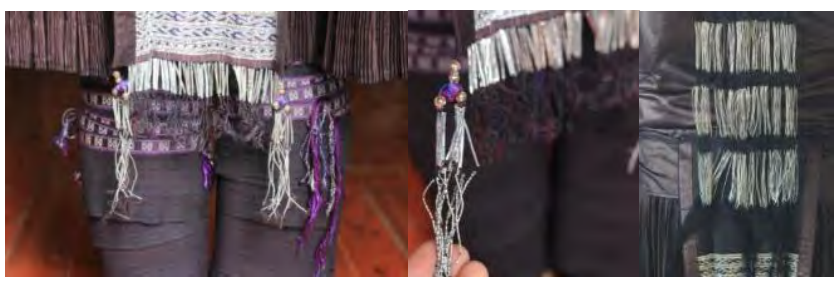

Fig. 14. Tin-coated part.

Due to its unique and complicated process, tin embroidery takes time and the production amount is small, so the price is naturally high. Its craftwork can not be measured by money, not only it represents the diligent and intelligent quality of a generation of tin embroidery Miao women, but also represents the inheritance of tin embroidery culture.

\section{THE BEAUTY OF TIN EMBROIDERY MATERIAL AND THE CREATION VIEW OF CRAFTSMANSHIP}

The entire geographical environment of Jianhe County, Guizhou Province, China belongs to the mountain top plateau. The territory belongs to the mid-subtropical monsoon climate zone. The climate and geography are suitable for the cultivation of cotton and lonicera edulis, it follows the objective natural conditions of the "Proper time and conditions" recorded in the "Kaogong Ji". The beautiful material and skillful craftwork are the subjective conditions, lonicera edulis, bovine gum and tin all reflect the characteristics of the beautiful material. They use lonicera edulis and lime as the main pigment to dyed fabric. Moreover, the purpose of dyeing the cloth with bovine gum is to increase the hardness of the fabric, so that the pattern embroidered by the tin material will be flat. We all know that the Miao people are favored silver, but they do not use silver as embroidered material, they use tin, because they also know that tin this material is cheap and good, it has good ductility and its color is like silver, bright as a mirror and is suitable for the main decorative materials of clothing. Although the tin embroidery process is complicated, the technique is the most exquisite. Each process of weaving, dyeing, picking and embroidering is carried out according to a certain method. The application of the cross stitching technique of weaving, and unstopped beating during the dyeing process is to make the fabric soft and flat, the mastery of the tin-plated force and so on, all reflect the delicate craftsmanship of the tin embroidery process. Proper time and conditions, beautiful material and skillful craftwork are vividly expressed in the tin embroidery process.

\section{CONCLUSION}

The classic creations of each ethnic group have their typical cultural and artistic characteristics. The tin embroidery process of the Jianhe Miao nationality in China is no exception. The embroidered women of Miao nationality inherit the craftsmanship of the art from generation to generation to their descendants through their industrious wisdom, so that we could see today's tin embroidery is still so simple but delicate. The creation view of Chinese tin embroidery craftsmanship is also worth learning by the current design community.

\section{REFERENCES}

[1] Zhou Ying. "Study on the Art of Tin embroidery of Jianhe Miao Nationality in Guizhou and Its Cultural Symbols[J]. Decoration, 2016, 02(274): 112-115. (in Chinese)

[2] Zhou Ying. "Analysis of the artistic characteristics of Miao people's tin embroidery in southeastern Guizhou"[J]. Silk, 2015,11(52):64-68. (in Chinese)

[3] Wang Bin. "Inheritance and innovation of traditional Miao people's tin embroidery art in southeastern Guizhou" [J]. Art Science and Technology: 89. (in Chinese)

[4] Huang Zhulan. "The Enlightenment of Guizhou Miao People's Traditional Tin Embroidery on Modern Garment Decoration Technology"[J]. Guizhou Ethnic Research, 2013, 8(4): 59-61. (in Chinese)

[5] Geng Xiaochen, "Study on the Art of Tin Products in China", Ph.D. Thesis, School of Art, Suzhou University, 2013. (in Chinese). 